\title{
Elections générales 2020 de la FMH
}

\section{Jürg Schlup}

Président de la FMH

\section{Lors de la Chambre médicale du 7 mai 2020, les déléguées et les délégués sont appe- lés à renouveler l'ensemble des organes de la FMH pour la nouvelle législature.}

Il s'agira d'élire:

a) les sept membres du Comité central de la FMH, dont la présidente ou le président et deux vice-président-e-s;

b) la présidente ou le président de l'ISFM;

c) la présidente ou le président et les quatre vice-président-e-s de la Commission de déontologie;

d) les cinq membres de la Commission de gestion;

e) les membres de l’Assemblée des délégués.

Les personnes déposant leur candidature aux fonctions a) à d) ont la possibilité de se présenter en publiant un portrait structuré dans le Bulletin des médecins suisses (BMS). Veuillez noter que conformément à l'article 22 des Statuts de la FMH, les personnes élues par la Chambre médicale ne peuvent exercer leur activité que jusqu'à la fin de l'année au cours de laquelle elles atteignent l'âge de 68 ans, sauf si la Chambre médicale décide d'une exception.

Un profil d'exigences à l'intention des candidat-e-s au Comité central et le formulaire pour la publication des portraits dans le BMS sont disponibles auprès des président-e-s des organisations représentées à la Chambre médicale ou de leurs secrétariats. En plus des conditions statutaires (titre de spécialiste et affiliation à la FMH), les candidat-e-s doivent notamment aussi avoir de l'expérience en matière de politique, de politique professionnelle et de direction et disposer de bonnes compétences linguistiques.

Pour la publication dans le BMS, nous avons besoin des informations concernant les candidat-e-s d'ici au 31 janvier 2020 au plus tard par courrier électronique à wahlen2020[at]fmh.ch. Passé ce délai, les informations reçues ne pourront plus être publiées dans le BMS. Pour toute question, veuillez également utiliser l’adresse électronique susmentionnée. 